\title{
Effect of patellar tendon release on squatting characteristics of tibiofemoral joint after total knee arthroplasty: a simulation analysis
}

Jian-ping Wang

Henan Polytechnic University

\section{Shihua Wang}

Henan Polytechnic University

\section{Yongqiang Yang}

Henan Polytechnic University

\section{Dong Guo}

Henan Polytechnic University

Jinlai Liu

The first affiliated hospital of henan polytechnic university

\section{Xu Chen}

The first affiliated hospital of henan polytechnic university

\section{Yangqing Wang}

Qiqihaer Medical College: Qiqihar Medical University

\section{Jiwu Chen}

Huashan Hospital Fudan University Department of Sports Medicine

Yu Li ( $D$ liyu@hpu.edu.cn )

Henan Polytechnic University https://orcid.org/0000-0001-5147-5223

\section{Research}

Keywords: TKA, Patellar tendon, Tibiofemoral joint, Squat movement, Dynamic finite element analysis

Posted Date: October 8th, 2020

DOl: https://doi.org/10.21203/rs.3.rs-87075/v1

License: (c) (i) This work is licensed under a Creative Commons Attribution 4.0 International License. Read Full License 


\section{Abstract}

\section{Background}

The objective of this paper was to study the patellar tendon release's effect on the squat movement characteristics of the tibiofemoral joint after TKA (total knee arthroplasty).

\section{Methods}

The dynamic FEM(finite element model) of the human knee joint with 30\% release of the upper end, lower end and both ends of the patellar tendon after TKA was established respectively, and the knee tibiofemoral joint of the squat movement simulation analysis.

Results

The results of simulation show that in the release of three different parts, comparing with the results of no release simulation, the average of lateral translation, superior translation, posterior translation, and the adduction of the femur relative to the tibia decreased by $20 \%, 17 \%, 17 \%$, and $12 \%$, respectively.

\section{Conclusion}

The average of external rotation of the femur relative to the tibia increased $24 \%$. By comparing the data after patellar tendon release and no release one, it can be concluded that the flexion degree of femur relative to the tibia was $4^{\circ}$ on average more than no release. Moderate release of the patellar tendon during TKA surgery is beneficial to improve the range of motion (ROM) of the femur relative to the tibia.

\section{Contributions To The Literature}

- The novelty of this paper is that we have carried out specific research on knee joint squatting, which is rare at present.

- By establishing the finite element model, this paper investigates the patellar tendon release's effect on the movement characteristics of the artificial tibiofemoral joint squat.

- In this paper, it can be concluded that the release of patellar tendon was favorable for high flexion(flexion angle greater than $120^{\circ}$ ), which indicated that the mobility of knee joint was improved after the patellar tendon release. The release of patellar tendon in different ends has different effects on the squatting motion characteristics of tibiofemoral joint.

\section{Introduction}

TKA (Total Knee Arthroplasty) is one of the most effective methods for the treatment of osteoarthritis, which relieves joint pain, improves joint function, and restores the patient's athletic ability. Related study [1] shows that the success rate of surgery is as high as $90 \%$. However, instability of the tibiofemoral joint is one of the common causes of knee dysfunction after TKA. At present, those who undergo revision 
surgery due to instability of the tibiofemoral joint account for about $10 \%-20 \%$ of the total knee revision, and the revision time is 4 years after surgery [2-4].The diseased knee extensor mechanism is one of the causes of instability of the tibial joint. The patellar tendon is an important component of the knee extension mechanism, which is connected to the lower femur and the tibial tuberosity, and controls the vertical distance of the patella relative to the joint space. Related studies [5-7] have shown that the length of patellar tendon has a certain reduction after TKA; simultaneously some studies $[6,8]$ have shown that the knee joint function is worse when the tendon is shortened, and the knee joint activity flexion becomes worse. It is usually more than $135^{\circ}$ for a natural person to complete a squatting and kneeling. However, the average ROM (range of motion) is $119.3^{\circ}$ at 6 months after TKA surgery, and the average ROM at 12 months after surgery is $122.9^{\circ}$ [9], which cannot satisfy the function of squatting and kneeling flexion. Can patellar tendon release be used to solve these problems during the operation?

In this paper, firstly, the simulation analysis of knee squat was performed by respectively $30 \%$ of the upper end, $30 \%$ of the lower end and $30 \%$ of the two ends of the patellar tendon releasing after TKA. Simultaneously, the data of the no-released model is compared with the data of the released model and other research results of knee joint. Secondly, there are few reports on patellar tendon release, and is patellar tendon release beneficial to flexion? Whether it affects the stability of knee extensor mechanism and the motion characteristic of the tibiofemoral joint, which were investigated in this paper.

\section{Materials And Methods}

\section{Establishment of finite element model}

This study was approved by the Health Sciences Institutional Review Board of our institution and informed consent was obtained from the subject.In this paper, the knee of a $10 \mathrm{~cm}$ above and below range of the knee joint center of a male healthy volunteer with a height of $173 \mathrm{~cm}$ and a weight of $60 \mathrm{~kg}$ was scanned by CT (computerized tomography) and MRI (magnetic resonance imaging), and the bone and soft tissue images of the knee joint were obtained. Then, based on the CT and MRI images, a $3 \mathrm{D}$ (three-dimensional)geometric anatomical model of the natural knee joint including the bone tissue and the main soft tissue was established. At the same time, the PFC prosthesis (Sigma PFC, Deputy Orthopedics, Indiana, USA) was assembled on the 3D geometric anatomical model of the knee joint (Figure.1(a)) according to the standard TKA. The finite element meshing of the geometric threedimensional model of the knee joint after TKA was established. In the FEM of the knee joint after TKA, the most of the unit types were hexahedrons (c3d8r, an 8-node linear brick element with reduced integration) of 29962, and very few were pentahedrons (C3D6, a 6-node linear triangular prism element) of 1690 and tetrahedrons (C3D4, a 4-node linear tetrahedron element) of 115, in which the total unit number: 31767, node number: 37031(as shown in Figure.1(b)). The volunteer was provided details of the study and signed an informed consent form. The specific model parameters are detailed in the simulation model that has verified by Wang Jian-ping $[10,11]$. 
Model was performed by simulating the release of both ends of the patellar tendon in the software Hypermesh 11.0 (Altair Corp., USA). The width of patellar tendon at the upper end was $6.84 \mathrm{~mm}$ of norelease one (Figure.2 (a)) and $4.788 \mathrm{~mm}$ of released one (Figure. 2(b)). Attachment height of patellar tendon at the lower end was $8.09 \mathrm{~mm}$ of no-release one (Figure.2 (c)) and $5.633 \mathrm{~mm}$ of released one (Figure.2 (d)). Figure.2 shows the FEM of the no-released model and released one of $30 \%$ the attachment area of the patellar tendon at both ends.

\section{Loading Conditions And The Setting Of Material Properties}

Properties for bone tissue and prosthetic material are defined as isotropic and linear elasticity. Ultra-high molecular polyethylene insert are of nonlinear elastoplastic deformable material properties [13,14]. The material properties of soft tissue are defined as nonlinear elastic materials [15]. The coefficient of friction between ultra high molecular polyethylene and cobalt chromium molybdenum material is defined as 0.04 [13]. For the femur, high molecular polyethylene liner, tibial plateau, patellar prosthesis and other soft tissues, seven surface contact pairs were defined in the FEM after TKA. The penalty function with weighted factor was adopted $[16,17]$.The squat of the knee joint was simulated by applying a quadriceps force of $400 \mathrm{~N}[10,18]$. The direction of the force was parallel to the femoral shaft, pointing to the starting point of the quadriceps muscle, and applying half of the human body's gravity along the knee joint force line $(0.5 \mathrm{BW})$. That is, a force perpendicular to the ground $300 \mathrm{~N}$ is applied at the center of the femoral head. The establishment of the above model and coordinate system, the setting of loading conditions and material properties are derived from the previously published papers [12].

\section{Results}

ABAQUS software (Dassault SIMULIA Corp., France) was used to calculate and analyze four different knee joint FEM under different flexion angles (within $\left.0-135^{\circ}\right)$. Four typical degrees $\left(0^{\circ}, 30^{\circ}, 90^{\circ}\right.$ and $\left.135^{\circ}\right)$ were extracted from the continuous simulation state of 0-135 degrees, respectively, and there state of the simulation models were shown in Figure.3.

\section{Medial-lateral translation of the femur relative to the tibia}

As shown in Figure.4, for the medial-lateral translation of the femur relative to the tibia, with the knee joint flexion, the medial-lateral translation of femur vs tibia changed alternately, and then stable increasingly changed after 100 degrees. After 100 degrees flexion, the femur continued to translate laterally relative to the tibia and present an increasing trend. Within 0-30 degrees, the medial-lateral translation of the released models was larger than that of no-released model; within 60-135 degrees, the medial-lateral translation of the released models was smaller than no-released one. At the 135 degrees of flexion, lateral translation of femur reached the maximum of $2.31 \mathrm{~mm}, 2.25 \mathrm{~mm}$, and $2.39 \mathrm{~mm}$ respectively for the upper-release, the lower-release and both-ends release. Compared with lateral translation $2.89 \mathrm{~mm}$ of no 
release one, it reached a decrease of $20 \%, 22 \%$ and $17 \%$, respectively. And the lateral translation of the femur relative to the tibia at $135^{\circ}$ flexion averagely decreased by $20 \%$, as shown in table 1 .

\section{Superior-inferior translation and internal-external rotation}

As shown in Figure.5(a), for the released and no-released models, with the knee joint flexion, the femur continued to translate upward relative to the tibia. During the whole knee flexion process, the femoral superior translation of upper-released model was less than that of no-released model. Within 20-120 degrees, the femoral superior translation of lower-released model was larger than that of no-released model; after 120 degrees of flexion, the femoral superior translation was smaller than no-released one. Within 20-110 degrees, the femoral superior translation of both-ends released model was larger than that of no-released model; after 110 degrees of flexion, the femoral superior translation was smaller than noreleased one. With the knee flexion of no-release model, the superior-inferior translation of the femur relative to the tibia exhibited an increasing trend. At 135 degrees of flexion, superior translation of femur relative to tibia reached the maximum of $4.92 \mathrm{~mm}, 4.88 \mathrm{~mm}$ and $4.47 \mathrm{~mm}$ respectively for the upperrelease, the lower-release and both-ends release. Compared with superior-translation of $5.75 \mathrm{~mm}$ of no release one, it reached a decrease of $14 \%, 15 \%$ and $22 \%$, respectively. And the average of the superior translation decreased by $17 \%$ at $135^{\circ}$, as shown in table 1.

As shown in Figure.5(b), for the released and no-released models, the femur rotated internally relative to the tibia at 0-10 degrees of knee flexion, and the femur rotated externally relative to the tibia at 20-135 degrees of flexion. Within 30-135 degrees, the femoral external rotation of the lower-release and the bothends release models were larger than that of no-released model, specially lower-released one was the maximal femoral external rotation in above three models; within 20-135 degrees, the femoral external rotation of the upper-released model was smaller than no-released model .With the knee flexion of norelease model, the internal- external rotation of the femur relative to the tibia exhibited an increasing trend at $0-90^{\circ}$, and tended to decrease trend after $90^{\circ}$ flexion. After the upper and lower releasing, the maximal femoral external rotation reached 11.46 degrees and 13.57 degrees respectively at 80 degrees of flexion, which decreased by $8 \%$ and increased by $9 \%$ respectively compared with 12.50 degrees of no-released model. After the both-ends releasing, the maximal femoral external rotation reached 13.21 degrees at 90 degrees of flexion, which was $6 \%$ higher than the maximal femoral external rotation of 12.50 degrees at 80 degrees flexion of no-released model. At 135 degrees of flexion, external rotation of femur relative to tibia reached the maximum of $5.16^{\circ}, 7.03^{\circ}$ and $7.39^{\circ}$ respectively for the upper-release, the lower-release and both-ends release. Compared with external rotation of $5.28^{\circ}$ of no release one, the external rotation of femur for upper-release reached a decrease by $2 \%$, and the external rotation of femur for lower-release and both-ends release reached an increase by $33 \%$ and $40 \%$, and the average of the external rotation increased by $24 \%$ at $135^{\circ}$, as shown in table 1 .

\section{Anterior-posterior translation and the adduction- abduction}

As shown in Figure.6(a), for the released and no-released models, the femur translated forward relative to the tibia within 0-110 degrees, the femur translated backward relative to the tibia within 110-135 degrees, 
and the posterior translation of no-released model showed an increasing trend after the knee flexion of $110^{\circ}$. With the knee joint flexion, the femoral anterior-posterior translation of released model relative to tibia decreased than no-released model, and the anterior-posterior translation of the both-ends release one was the smallest than that of no-release one. At 135 degrees of flexion, posterior translation of femur relative to tibia reached the maximum of $10.57 \mathrm{~mm}, 9.58 \mathrm{~mm}$ and $9.14 \mathrm{~mm}$ respectively for the upperrelease, the lower-release and both-ends release. Compared with posterior-translation of $11.71 \mathrm{~mm}$ of no release one, it reached a decrease of $10 \%, 18 \%$ and $22 \%$, respectively. And the average of the posterior translation decreased by $17 \%$ at $135^{\circ}$, as show in table 1 .

As shown in Figure.6(b), for the released and no-released models, the femur adducted relative to the tibia within 0-20 degrees of flexion, the femur abducted relative to the tibia within 30-80 degrees of flexion, and the femur adducted relative to the tibia within 90-135 degrees of flexion. The femoral abduction of released model decreased than that of no-released model within 30-80 degrees; the femoral adduction of released model decreased than that of no-released model at 90-135 degrees. The adduction of the noreleased model showed an increasing trend after 90 degrees of knee flexion. At the 135 degrees of flexion, the adduction of femur relative to tibia reached the maximum of $6.25^{\circ}, 6.21^{\circ}$, and $6.48^{\circ}$ respectively for the upper-release, the lower-release and both-ends release. Compared with adduction of $7.17^{\circ}$ of no release one, it reached a decrease of $13 \%, 13 \%$ and $10 \%$, respectively. And the average of the adduction decreased by $12 \%$ at $135^{\circ}$, as show in table 1 .

\section{Discussion}

In this paper, the effect of the patellar tendon release of the upper end, the lower end, and both end release of $30 \%$ on the movement characteristics of the tibiofemoral joint squat was investigated. Furthermore, the data of the no-released model was compared with the data of the released model and other research results of knee joint.

\section{Medial-lateral translation of the femur relative to the tibia}

In the knee joint movement after TKA of Koji [19], with the knee joint flexion, the femur first translated medially and then translated laterally relative to the tibia, and there is a trend of lateral translation for the femur. In the natural knee joint study of Michal Kozanek [20] and Chi-hui Chen [21], the femur relative to the tibia also showed a trend of lateral translation. Their results of the general movement trend of femur relative to the tibia were basically consistent with the results of the released model in this paper. The TKA study results of Koji[19] showed that the lateral translation was the largest $(18 \mathrm{~mm})$ at 120 degrees of flexion; at 135 degrees of flexion in this paper, the maximal lateral translation of the femur relative to the tibia was about $11.71 \mathrm{~mm}$ before the release of the patellar tendon, the maximal lateral translation was about $10.57 \mathrm{~mm}$ after the release of the patellar tendon; the maximal lateral translation results of Koji[19] was different from this paper, the reason maybe related to the using different knee prosthesis types.(the patients in Koji's paper had undergone bi-cruciate stabilized fixed-bearing TKA). In the natural knee joint study of Chi-hui Chen[21], the maximal lateral translation was about $3 \mathrm{~mm}$, which was also basically 
consistent with the maximal lateral translation $(2.39 \mathrm{~mm})$ after the release of the patellar tendon in this paper. Meantime, the knee flexion's improvement level was directly decided by the limitation flexion capacity after 100 degrees flexion. In order to study the relationship between medial-lateral translation and the improvement of high flexion, we focus on this relationship when the flexion is greater than 100 degrees for released and no-released models. So we extract the relationship from Fig. 4, as shown in Figure.7.

As shown in Figure.7, for all above four models, the medial-lateral translation of the femur relative to the tibia exhibited an increasing trend. It is obvious that the lateral translation of no-released model was larger than that of released model at the same flexion angle. This means that only the small amount of lateral translation was required to achieve the same flexion angle than the no-release one. The average value of lateral translation of the upper-end-release, the lower-end-release, and both-ends-release was taken as the lateral translation of the released model, and compared with the lateral translation of the noreleased model, as shown in Figure. 8 (a). When the degree of flexion is greater than $100^{\circ}$, the lateral translation of the released and no-released model increases approximately linearly and its variation trend is stable, in which $\mathrm{N}$-trendline means no-released trendline and R-trendline means released trendline. According to the trend line in Figure.8(a), it can be concluded that: at the same translation( $T$ ), the corresponding flexion degree of released model $(\beta)$ is larger than that of no-released model ( $\alpha)$, therefore, there are larger flexion capability for released TKA knees.

\section{Superior-inferior translation and internal-external rotation}

For the superior-inferior translation of the femur relative to the tibia, the nature knee studies of Michal Kozanek [20] and Chi-hui Chen [21] showed that the femur translated upward in the early flexion. Their results of the femoral superior translation were basically consistent with that of the released model in this paper. Related studies [22] also showed that the femur translated upward with the knee flexion, and the maximum flexion angle of the knee was 90 degree, at the same time, the maximum superior translation was about $6.17 \mathrm{~mm}$ in their researches, which was basically consistent with this paper (the maximum knee flexion was 135 degrees, and the maximum superior translation was $4.92 \mathrm{~mm}$ ). Similarly, we focus on this relationship when the flexion is greater than 100 degrees for released and no-released models. It can also be predicted that the released flexion degrees was larger $5^{\circ}$ than the no-released one after 100 degrees of flexion at table 2.

For the internal-external rotation of the femur relative to the tibia, the post-TKA knee studies of Koji[19] showed, with the flexion of the knee joint, the femur is always rotated externally relative to the tibia. The femur of the released model showed rotated externally except for 0-10 degrees in this paper, which consistent with the general trend of Koji [19]. In this paper, the external rotation of the femur of upperreleased and lower-released reached the maximum at 80 degrees of flexion, the both-ends release reached the maximum at 90 degrees of flexion, and the lateral rotation trend of the four models were first increased and then decreased. It can also be predicted that the released flexion degrees was larger $4.8^{\circ}$ than the no-released one after 100 degrees of flexion at table 2. 


\section{Anterior-posterior translation and the adduction- abduction}

For the anterior-posterior translation of the femur relative to the tibia, Silvia Pianigiani [23] studied knee squatting after four TKA respectively, the results showed that the femur translated anteriorly relative to tibia. In this paper, within 0-110 degrees of flexion, the femur of released models also translated anteriorly, which was consisted with the no-released model; however, within 110-135 degrees of flexion, the femur translated posteriorly. In the natural knee joint study of Kesys [24], with the flexion of the knee joint, the femur continued to translated posteriorly relative to the tibia; while the femur of released and no-released models translated posteriorly until 110 degrees; different reason may be the femoral anterior-posterior translation has changed after TKA. In this study when the knee flexion is greater than $110^{\circ}$, the posterior translation of the released and no-released models increased linearly and their variation trend were stable. It can also be predicted by that the released flexion degrees was larger $1^{\circ}$ than the no-released one after 100 degrees of flexion, as shown in table 2.

For the adduction-abduction of the femur relative to the tibia, the results of Silvia Pianigiani [23] showed that the use of different knee prostheses resulted in a great difference in adduction- abduction of femur relative to tibia, which indicated that the type of prosthesis had a great influence on the movement of knee joint. The results of K.E. Moglo [25]showed that the femur adducted and then abducted, In this paper, within 30-80 degrees, the femur adducted relative to the tibia; within 90-135degrees, the femur abducted, which was basically constited with the results of K.E. Moglo. In this study, similarly, we focus on this relationship when the flexion is greater than 100 degrees for released and no-released models. It can also be predicted by that the released flexion degrees was larger $4^{\circ}$ than the no-released one after 100 degrees of flexion at table 2 .

By comparative analysis, it can be concluded that the release of patellar tendon was favorable for high flexion(flexion angle greater than $120^{\circ}$ ). And the femur of released models relative to tibia for the mediallateral translation, superior-inferior translation, internal-external rotation, anterior-posterior translation, and adduction-abduction were favorable for high flexion. As shown in table 3.

By comparative analysis, the change of flexion angle of the released and no-released models was obtained. Among them, when the flexion is greater than 100 degrees, at the same lateral translation, the flexion degree of released model increased by $5.4^{\circ}$ on average compared with no-released model; At the same superior translation, the flexion degree of released model increased by $5^{\circ}$ on average; At the same external rotation, the flexion degree of released model increased by $4.8^{\circ}$ on average; At the same posterior translation, the flexion degree of released model increased by $1^{\circ}$ on average; At the same adduction, the flexion degree of released model increased by $4^{\circ}$ on average as shown in table 4 below. In this paper the total average ROM of the released models increased by $4^{\circ}$, indicating that the release of the patellar tendon is favorable for the high flexion.

The limitations of this study should be considered. Only $30 \%$ of the model was released, and other degrees of releasing were not considered. In this paper, the FEM of the knee after TKA was established on 
the basis of considering the main bone tissue and soft tissue. Although the medial and lateral transverse patellofemoral ligament was added, the joint capsule, hamstring or gastrocnemius muscle did not take into account for the knee joint activity. Subsequent research should take these shortcomings into account to make the model more physiologically compatible.

\section{Conclusions}

The effect of different parts of the patellar tendon release on the movement characteristics of the tibiofemoral joint was analysis in this paper. The femoral external rotation of the upper end released relative to the tibia was smaller than no-released model, and the lower-released and both-end released were larger. The femoral superior translation of the upper-released relative to the tibia was smaller than no-released one, and the femoral superior translation of the lower-released and both-end released were larger, After the patellar tendon releasing, the medial-lateral translation, external rotation, anterior-posterior translation and adduction-abduction of femur were decreased compare with the no-released one. However, the flexion of the released model was increased than no-released one. At the same lateral translation, superior translation, external rotation, posterior translation and adduction, the flexion degree of released model increased by $5.4^{\circ}, 5^{\circ}, 4.8^{\circ}, 1^{\circ}, 4^{\circ}$ on average compared with no-released model, respectively. And it can be inferred that the flexion degree of femur relative to the tibia totally was $4^{\circ}$ on average more than no release. Therefore, in order to ensure that the femur has a larger ROM relative to the tibia during TKA surgery, it is recommended that both- ends of the patellar tendon should be moderately released with reference to the data in this paper. At the same time, the results of this study can provide reference for the study of knee joint pathology, rehabilitation and related surgery.

\section{Declarations}

\section{Ethics approval and consent to participate}

This study was approved by the Health Sciences Institutional Review Board of our institution and informed consent was obtained from the subject.

\section{Consent for publication}

This study was consented for publication.

\section{Availability of data and material}

The data and material was available in this study.

\section{Competing interests}

The authors declare no conflicts of interests.

\section{Funding}


This investigation was funded by a grant from the National Institutes of Health and supported by National Natural Science Foundation of China (31370999). (Information for disclosures can be taken from the online abstract system after entering all authors.

\section{Author Contributions}

Conceptualization: Jianping Wang.

Data curation: Shihua Wang and Yu Li.

Investigation: Jianping Wang, Jinlai Liu, Xu Chen, and Jiwu Chen.

Methodology: Jianping Wang and Yu Li.

Resources: Jianping Wang.

Software: Jianping Wang, Shihua Wang and Yongqiang Yang.

Supervision: Jianping Wang and Yu Li.

Validation: Shihua Wang, Yanqing Wang, Dong Guo and Jiwu Chen.

Writing - original draft: Jianping Wang.

Writing - review \& editing $₫$ Shihua Wang, Yongqiang Yang, Dong Guo, and Yu Li.

\section{Conflicts of interest}

The authors declare no conflicts of interests.

\section{Acknowledgements}

This investigation was supported by National Natural Science Foundation of China (31370999).

\section{References}

1. Knutson K, Lewold S, Robertsson O, Lidgren L. The swedish knee arthroplasty register: a nation-wide study of 30,003 knees 1976-1992. ActaOrthopaedica 1994; 65(4):375-386.

2. Vince KG. Why knees fail. J Arthroplasty. 2003;18:39-44.

3. Goldberg VM, Figgie MP, Figgie HE, Sobel M. The results of revision total knee arthroplasty. ClinOrthop. 1988;226:86-92.

4. Sharkey PF, Lichstein PM, Shen C, Tokarski AT, Parvizi J. Why Are Total Knee Arthroplasties Failing Today-Has Anything Changed After 10 Years? The Journal of Arthroplasty. 2014;29(9):1774-8. 
5. Aglietti P, BuzziR,Zaccherotti G, De Biase P. Patellar tendon versus doubled semitendinosus and gracilis tendons for anterior cruciate ligament reconstruction. Am J Sports Med. 1994;22:211-27.

6. Chougule SS, Stefanakis G, Stefan SC, Rudra S, Tselentakis G. Effects of fat pad excision on length of the patellar tendon after total knee replacement. J Orthopaedics. 2015;4:197-204.

7. Weale AE. The length of the patellar tendon after unicompartmental and total knee replacement. The Bone Joint Journal. 1999;81:790-5.

8. Davies GS, Van Duren B, Shorthose M, Roberts PG, Morley JR. Monk AP.Changes in patella tendon length over 5 ?years after different types of knee arthroplasty. Knee Surgery, Sports Traumatology, Arthroscopy.2016.

9. Zhou Z, Yew KSA, Arul E, Chin PL, Tay KJD, Lo NN, Yeo SJ. Recovery in knee range of motion reaches a plateau by 12 months after total knee arthroplasty. 23. Sports Traumatology: Knee Surgery; 2015. pp. 1729-33.

10. Wang J, Tao K, Li H, Wang C. Modelling and analysis on biomechanical dynamic characteristics of knee flexion movement under squatting. The Scientific World Journal 2014; 2014:1-14.

11. Wang JP, Guo D, Wang SH, Yang YQ, Li G. Structural stability of a polyetheretherketone femoral component-A 3D finite element simulation. Clin Biomech. 2019;70:153-7.

12. Wang J, Yang Y, Guo D, et al. The Effect of Patellar Tendon Release on the Characteristics of Patellofemoral Joint Squat Movement: A Simulation Analysis. Applied Sciences 2019;9(20).

13. Godest AC, Beaugonin M, Haug E, Taylor M, Gregson PJ. Simulation of a knee joint replacement during a gait cycle using explicit finite element analysis. Journal of biomechanics. 2002;35(2):26775 .

14. Taylor M, Barrett DS. Explicit finite element simulation of eccentric loading in total knee replacement. ClinOrthop. 2003;414:162-71.

15. Pena E, Calvo B, Martinez MA, Doblare M. A three-dimensional finite element analysis of the combined behavior of ligaments and menisci in the healthy human knee joint. J Biomechanics. 2006;39:1686-701.

16. Halloran JP, Petrella AJ, Rullkoetter PJ. Explicit finite element modeling of total knee replacement mechanics. J Biomechanics. 2005;38:323-31.

17. Bustince HJ. Fernandez, Burillo P Penalty Function in Optimization Problems: A Review of Recent Developments. Soft Computing Based Optimization and Decision Models 2018.

18. Li G, Most E, Otterberg E, Sabbag K, Zayontz S, Johnson T, Rubash H. Biomechanics of posteriorsubstituting total knee arthroplasty: an in vitro study. ClinOrthop. 2002;404:214-25.

19. Koji M, Satoshi H, Ken O, Hirotaka G, Yifeng W, Satoru I. Knee kinematics in bi-cruciate stabilized total knee arthroplasty during squatting and stair-climbing activities. Journal of Orthopaedics. 2018;15(2):650-4.

20. Kozanek M, Hosseini A, Liu F, Van de Velde SK, Gill TJ, Rubash HE, Li G. Tibiofemoral kinematics and condylar motion during the stance phase of gait. Journal of biomechanics. 2009;42(12):1877-84. 
21. Chen CH, Li JS, Hosseini A, Gadikota HR, Kozanek M, Gill TJ, Li G. Tibiofemoral Kinematics of the Knee During the Stance Phase of Gait After ACL Deficiency. Proceedings of the ASME 2011 Summer Bioengineering Conference SBC2011 2011; 22-25.

22. Hanson GR, Suggs JF, Freiberg AA, Durbhakula S, Li G. Investigation of in vivo 6dof total knee arthoplasty kinematics using a dual orthogonal fluoroscopic system. J Orthop Res. 2010;24:974-81.

23. Pianigiani S, Chevalier Y, Labey L, Pascale V, Innocenti B. Tibio-femoral kinematics in different total knee arthroplasty designs during a loaded squat: a numerical sensitivity study. J Biomech. 2012;45:2315-23.

24. Keays SL, Sayers M, Mellifont DB, Richardson C. Tibial displacement and rotation during seated knee extension and wall squatting: a comparative study of tibiofemoral kinematics between chronic unilateral anterior cruciate ligament deficient and healthy knees. Knee. 2013;20:346-53.

25. Moglo KE, Shirazi-Adl A. Cruciate coupling and screw-home mechanism in passive knee joint during extension-flexion. Journal of biomechanics. 2009;38:1075-83.

\section{Tables}

Table. 1 The value of the femur relative to the tibia at $135^{\circ}$ flexion

\begin{tabular}{|c|c|c|c|c|c|}
\hline & $\begin{array}{l}\text { Lateral } \\
\text { translation }\end{array}$ & $\begin{array}{l}\text { Superior } \\
\text { translation }\end{array}$ & \multicolumn{2}{|c|}{$\begin{array}{l}\text { PosteriorExternal } \\
\text { Translation } \\
\text { rotation }\end{array}$} & $\begin{array}{l}\text { Adduction } \\
\text { abduction }\end{array}$ \\
\hline Before release & $2.89 \mathrm{~mm}$ & $5.75 \mathrm{~mm}$ & $11.71 \mathrm{~mm}$ & $5.28^{\circ}$ & $7.17 \mathrm{~mm}$ \\
\hline Upper release & $2.31 \mathrm{~mm}$ & $4.92 \mathrm{~mm}$ & $10.57 \mathrm{~mm}$ & $5.16^{\circ}$ & $6.25 \mathrm{~mm}$ \\
\hline Lower release & $2.25 \mathrm{~mm}$ & $4.88 \mathrm{~mm}$ & $9.58 \mathrm{~mm}$ & $7.03^{\circ}$ & $6.21 \mathrm{~mm}$ \\
\hline Both release & $2.39 \mathrm{~mm}$ & $4.47 \mathrm{~mm}$ & $9.14 \mathrm{~mm}$ & $7.39^{\circ}$ & $6.48 \mathrm{~mm}$ \\
\hline average after release & $-0.57 \mathrm{~mm}$ & $-0.99 \mathrm{~mm}$ & $\begin{array}{l}-1.95 \mathrm{~mm} \\
+1.25^{\circ}\end{array}$ & & $-0.86 \mathrm{~mm}$ \\
\hline $\begin{array}{l}\text { Average percentage after } \\
\text { release }\end{array}$ & $-20 \%$ & $-17 \%$ & $-17 \%$ & $4 \%$ & $-12 \%$ \\
\hline
\end{tabular}


Table.2 Flexion degree before and after releasing at 100-140 degree of the same translation 


\begin{tabular}{|c|c|c|c|c|c|}
\hline & & Medial-lateral & translation & & \\
\hline$T \rrbracket m m \rrbracket$ & -0.5 & -1 & -1.5 & -2 & -2.5 \\
\hline BR & $105^{\circ}$ & $114^{\circ}$ & $123^{\circ}$ & $128^{\circ}$ & $134^{\circ}$ \\
\hline AR & $108^{\circ}$ & $117^{\circ}$ & $131^{\circ}$ & $135^{\circ}$ & $140^{\circ}$ \\
\hline $\mathrm{Al}$ & $3^{\circ}$ & $3^{\circ}$ & $8^{\circ}$ & $7^{\circ}$ & $6^{\circ}$ \\
\hline \multirow[t]{2}{*}{ TA } & & $5.4^{\circ}$ & & & \\
\hline & & Superior-inferior & translation & & \\
\hline$T \otimes m m \rrbracket$ & 4 & 4.2 & 4.5 & 4.6 & 4.8 \\
\hline BR & $111^{\circ}$ & $107^{\circ}$ & $118^{\circ}$ & $120^{\circ}$ & $121^{\circ}$ \\
\hline$A R$ & $100^{\circ}$ & $113^{\circ}$ & $118^{\circ}$ & $132^{\circ}$ & $140^{\circ}$ \\
\hline $\mathrm{Al}$ & $-11^{\circ}$ & $5^{\circ}$ & $0^{\circ}$ & $12^{\circ}$ & $19^{\circ}$ \\
\hline \multirow[t]{2}{*}{ TA } & & $5^{\circ}$ & & & \\
\hline & & Internal -external & rotation & & \\
\hline$T \nabla m m \rrbracket$ & -12 & -10 & -8 & -2 & -6.5 \\
\hline BR & $100^{\circ}$ & $115^{\circ}$ & $125^{\circ}$ & $128^{\circ}$ & $135^{\circ}$ \\
\hline AR & $104^{\circ}$ & $117^{\circ}$ & $131^{\circ}$ & $135^{\circ}$ & $140^{\circ}$ \\
\hline $\mathrm{Al}$ & $4^{\circ}$ & $2^{\circ}$ & $6^{\circ}$ & $7^{\circ}$ & $5^{\circ}$ \\
\hline \multirow[t]{2}{*}{ TA } & & $4.8^{\circ}$ & & & \\
\hline & & Anterior-posterior & translation & & \\
\hline$T \rrbracket m m \rrbracket$ & 3 & -1 & -4 & -6 & -8 \\
\hline BR & $110^{\circ}$ & $116^{\circ}$ & $123^{\circ}$ & $128^{\circ}$ & $132^{\circ}$ \\
\hline AR & $105^{\circ}$ & $116^{\circ}$ & $126^{\circ}$ & $131^{\circ}$ & $136^{\circ}$ \\
\hline $\mathrm{Al}$ & $-5^{\circ}$ & $0^{\circ}$ & $3^{\circ}$ & $3^{\circ}$ & $4^{\circ}$ \\
\hline \multirow[t]{2}{*}{ TA } & & $1^{\circ}$ & & & \\
\hline & \multicolumn{2}{|c|}{ adduction } & abduction & & \\
\hline $\mathrm{T} \otimes \mathrm{mm} \rrbracket$ & 2 & 3 & 4 & 5.5 & 6 \\
\hline BR & $101^{\circ}$ & $11^{\circ}$ & $120^{\circ}$ & $126^{\circ}$ & $129^{\circ}$ \\
\hline AR & $105^{\circ} 1$ & & $118^{\circ}$ & $133^{\circ}$ & $138^{\circ}$ \\
\hline $\mathrm{Al}$ & $4^{\circ} 2^{\circ}$ & & $-2^{\circ}$ & $7^{\circ}$ & $9^{\circ}$ \\
\hline
\end{tabular}




TA $4^{\circ}$

T means the same translation, $B R$ means before release, AR means after release, Al means average increase, and TA means total average. $\mathrm{Al}=\mathrm{AR}-\mathrm{BR}, \mathrm{TA}=[\mathrm{S}(\mathrm{Al})] / 5$.

Table. 3 Whether the released models were favorable to the flexion $\left(100^{\circ}-120^{\circ}\right.$ and after $\left.120^{\circ}\right)$

\begin{tabular}{|lll|}
\hline flexion & $100^{\circ}-120^{\circ}$ & $>120^{\circ}$ \\
\hline Medial-lateral translation & + & + \\
\hline Superior-inferior translation & - & + \\
\hline internal-external rotation & + & + \\
Anterior-posterior translation & - & + \\
\hline Adduction-abduction & + & + \\
\hline
\end{tabular}

- indicates that the flexion motion is unfavorable after releasing, and + indicates that the flexion motion is favorable after releasing

Table.4 Changes in flexion of patellar tendon after patellar tendon release

\begin{tabular}{|lllllll|}
\hline & $\begin{array}{l}\text { Medial- } \\
\text { lateral } \\
\text { translation }\end{array}$ & $\begin{array}{l}\text { Superior- } \\
\text { inferior } \\
\text { translation }\end{array}$ & $\begin{array}{l}\text { Internal- } \\
\text { external } \\
\text { rotation }\end{array}$ & $\begin{array}{l}\text { Anterior- } \\
\text { posterior } \\
\text { translation }\end{array}$ & $\begin{array}{l}\text { Adduction } \\
\text { abduction }\end{array}$ & $\begin{array}{l}\text { Total } \\
\text { average }\end{array}$ \\
$\begin{array}{l}\text { The average } \\
\text { Change in } \\
\text { flexion }\end{array}$ & & & & & & \\
& $5.4^{\circ}$ & $5^{\circ}$ & $4.8^{\circ}$ & $1^{\circ}$ & $5^{\circ}$ & $4.2^{\circ}$ \\
\hline
\end{tabular}

\section{Figures}



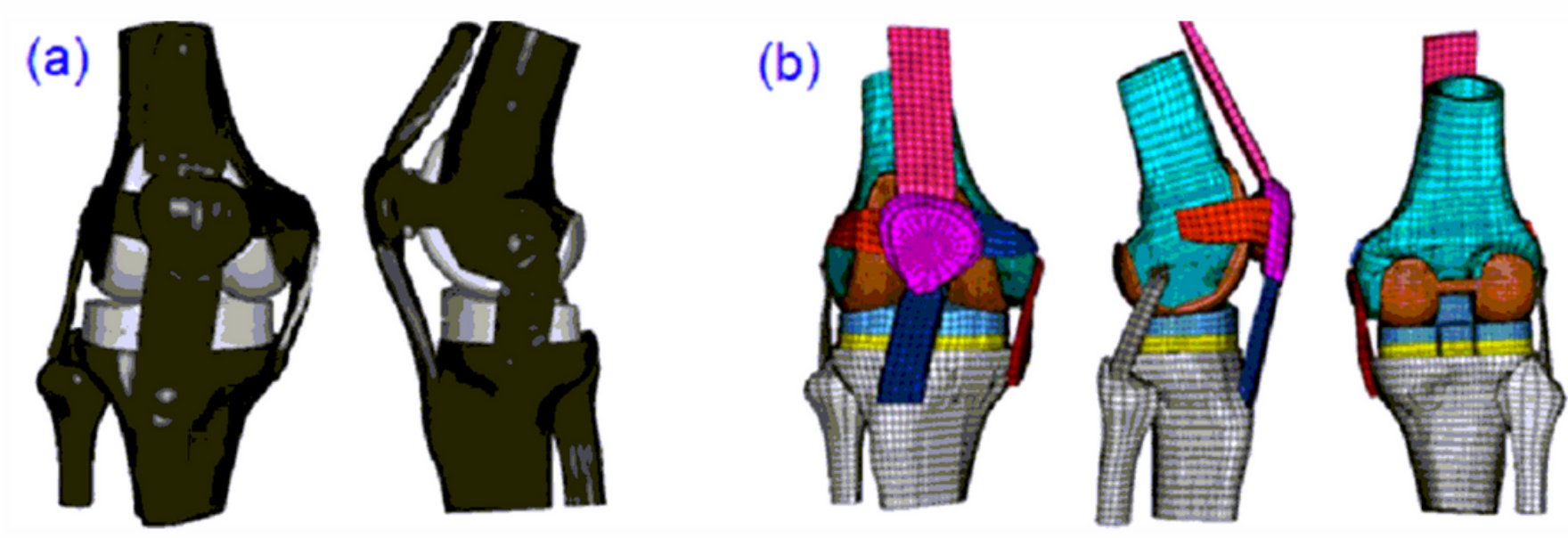

Figure 1

(a) 3D geometric anatomical model of knee joint after TKA; (b) finite element model of knee joint after TKA [12].
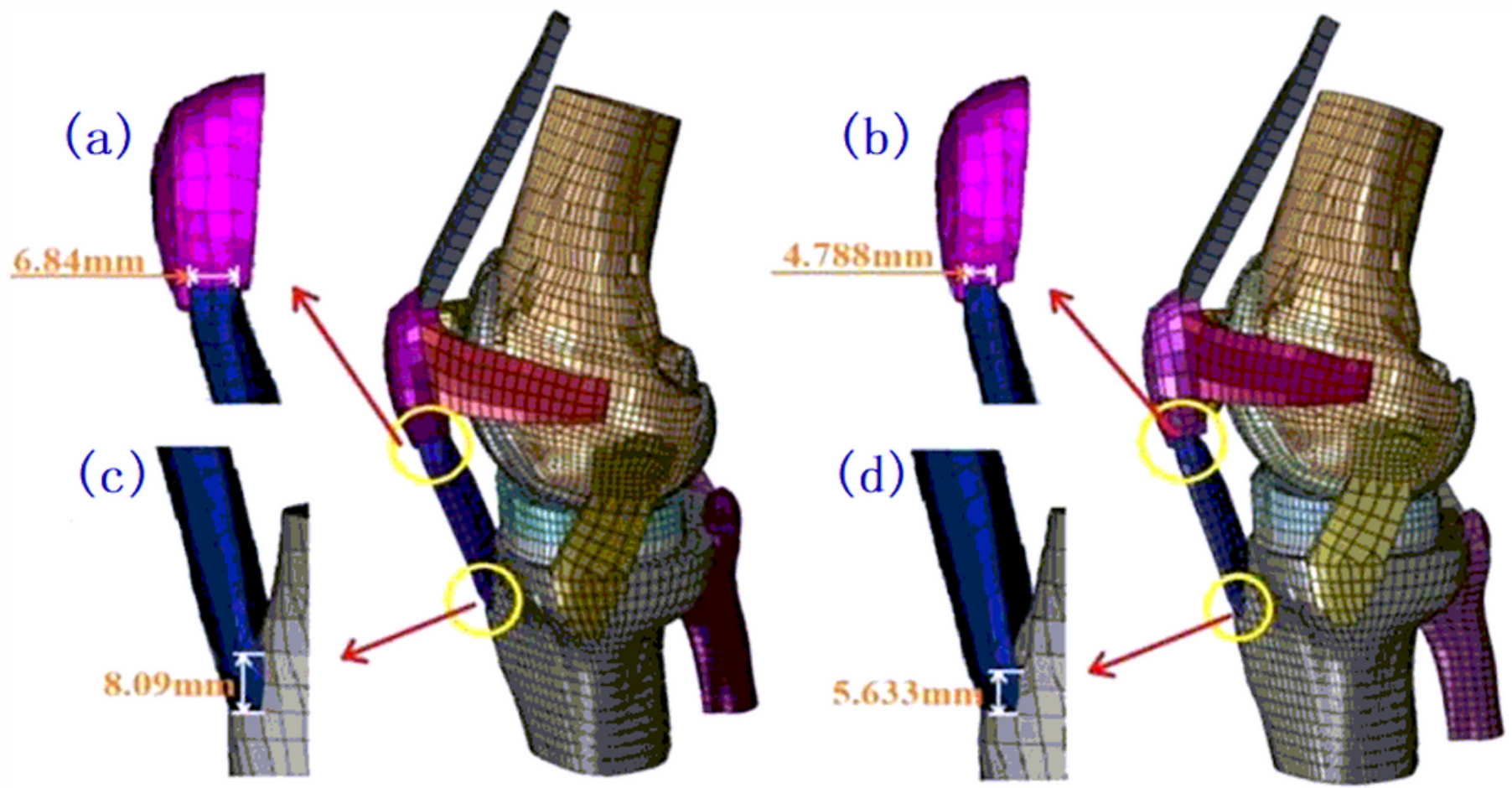

Figure 2

The finite element model of patellar tendon [12]: (a) the upper before release; (b) the upper released; (c) the lower before release; $(d)$ the lower released. 

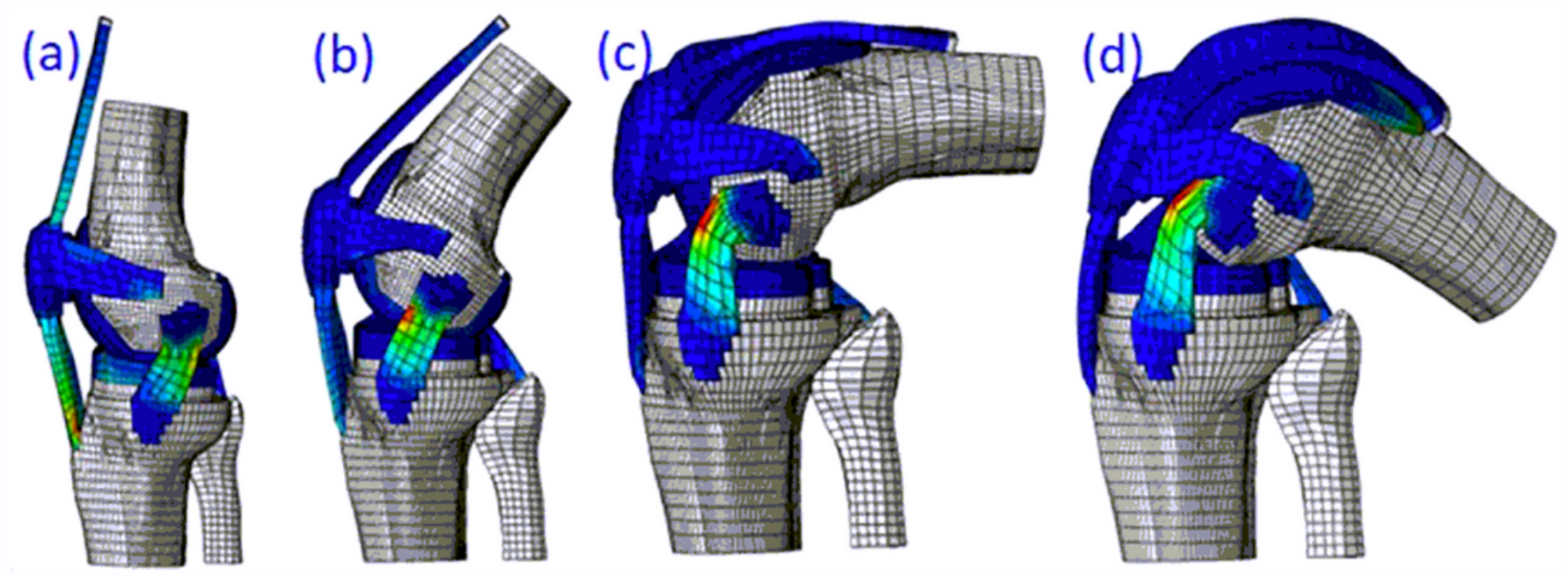

Figure 3

A sample of simulation states after TKA. Flexion degrees: (a) $0^{\circ}$ (b) $30^{\circ}$ (c) $90^{\circ}$ (d) $135^{\circ}[12]$.

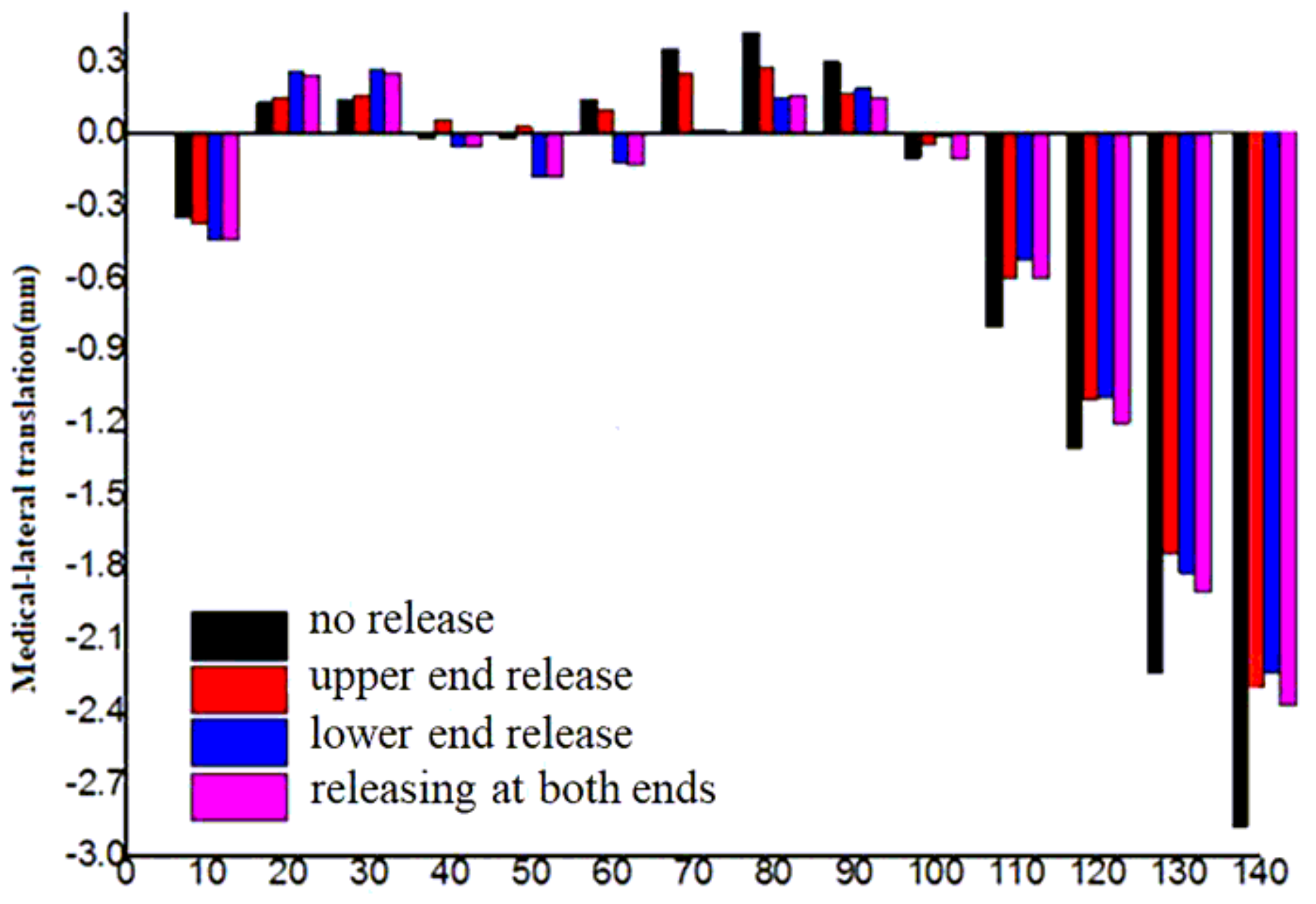

Flexion of the femur to the tibia(degree) 
Figure 4

Tibiofemoral medial-lateral translation at flexion for the three different releases and no release patellar tendon.
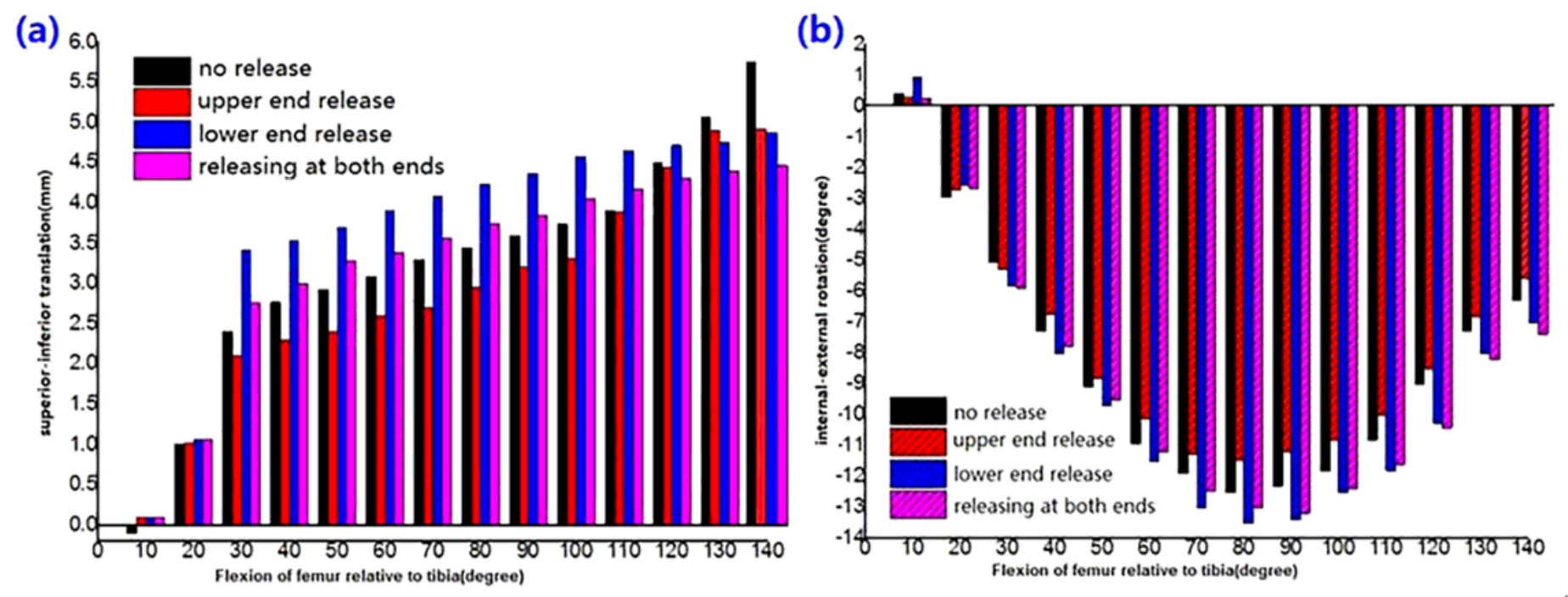

Figure 5

Tibiofemoral movement at different flexion for the release and no release patellar tendon. (a)superiorinferior translation(the femur relative to the tibia) (b)interal-external rotation(the femur relative to the tibia)
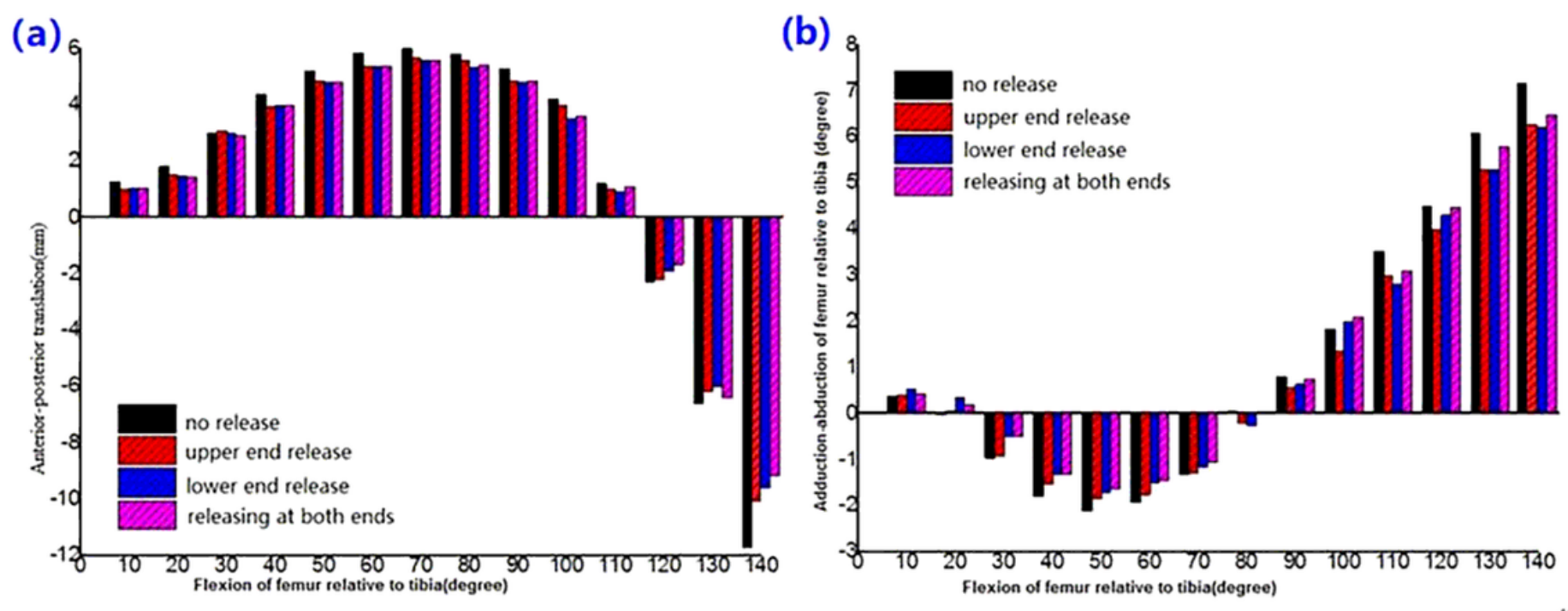

\section{Figure 6}

Tibiofemoral movement at different flexion for the release and no release patellar tendon. (a)anteriorposterior translation (the femur relative to the tibia) (b)adduction-abduction(the femur relative to the tibia) 


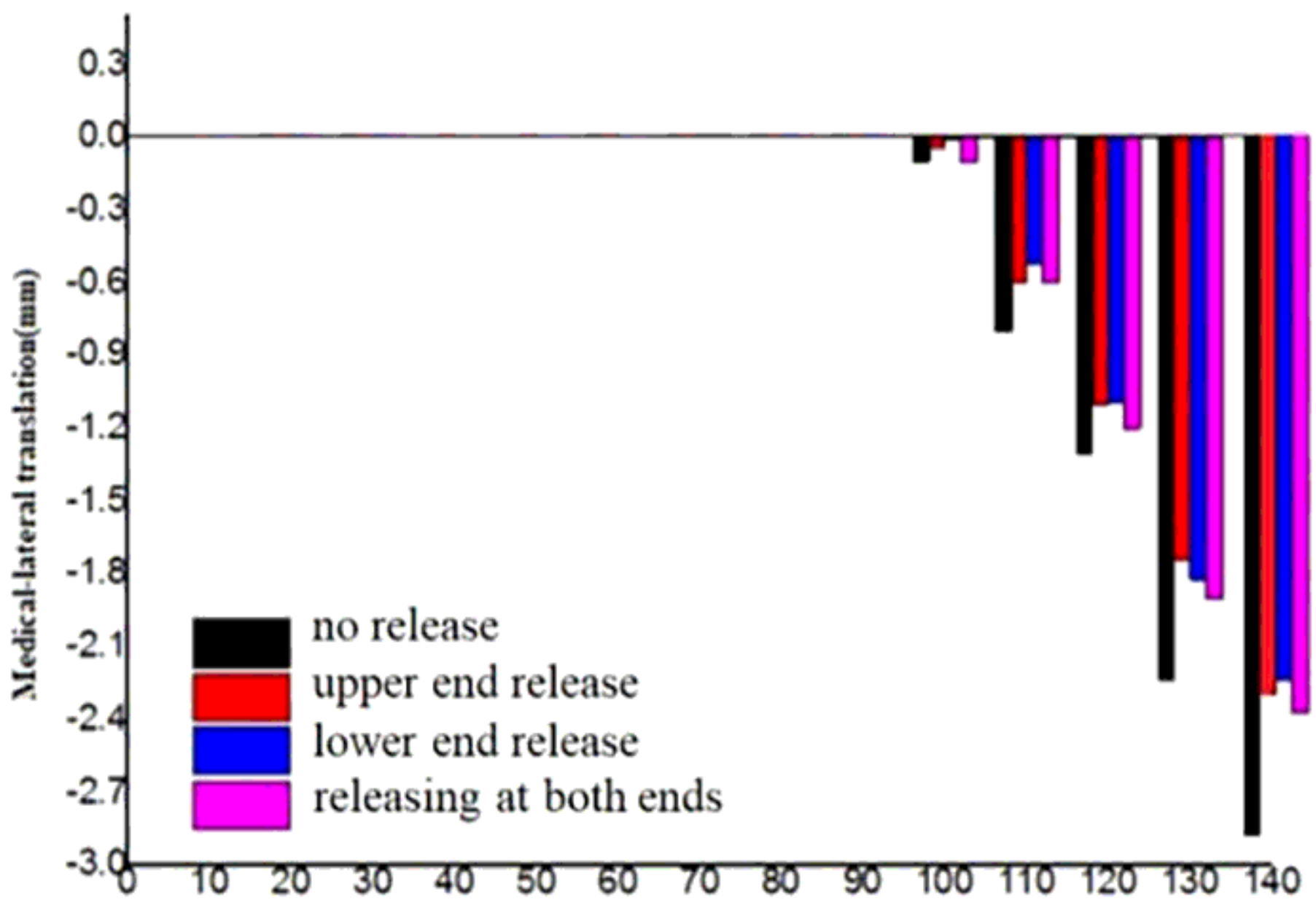

Flexion of the femur to the tibia(degree)

Figure 7

Tibiofemoral medial-lateral translation at 100-140 degrees for the release and no release patellar tendon
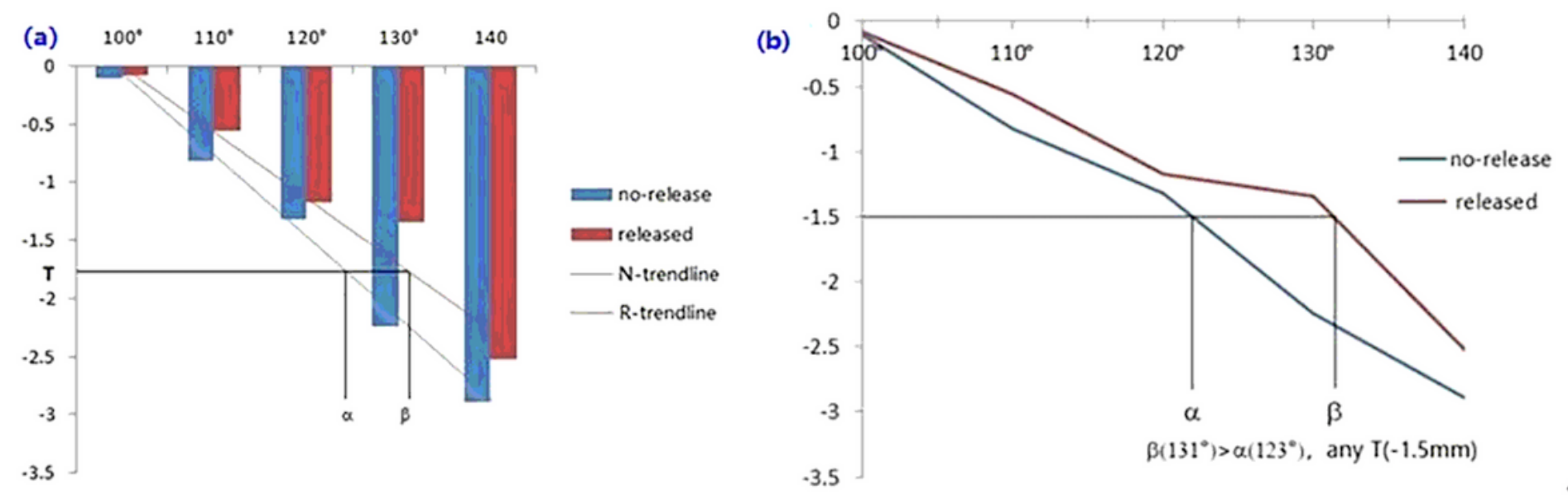

Figure 8 
(a) Tibiofemoral medial-lateral translation at 100-140 degrees for the released and no-release.

(b)Tibiofemoral medial-lateral translation chart at 100-140 degrees for the released and no-release T means any same translation. a means under any $T$, the corresponding flexion degree before release. $\beta$ means under any $T$, the corresponding flexion degree after release. Example: $\beta\left(131^{\circ}\right)>a\left(123^{\circ}\right), T(-1.5 \mathrm{~mm})$. 